\title{
Poly(methyl methacrylate-co-N-vinyl-2-pyrrolidone polymer as inhibitor for Mild Steel Corrosion in Acidic Media
}

\author{
Xiqing Zhao ${ }^{1, *}$, Jun Xiong ${ }^{2}$, Shaowei Zhu ${ }^{3}$, Xiaosong Zhao ${ }^{3}$, Ambrish Singh ${ }^{4}$ \\ ${ }^{1}$ Qiqihar Medical University, Qiqihar, Heilongjiang Province, 161006, P.R China \\ ${ }^{2}$ No.5 Testing Institute of Beijing Construction Quality Co., Ltd., Beijing, 100000, P.R. China \\ ${ }^{3}$ Qiqihar University, Heilongjiang Province, 161006, China \\ ${ }^{4}$ School of Materials Science and Engineering, Southwest Petroleum University, 8 Xindu district- \\ 610500, Chengdu city, Sichuan province, P.R. China. \\ *E-mail: zhaoxiqingssl@ sina.com
}

doi: $10.20964 / 2019.01 .46$

Received: 9 September 2018 / Accepted: 25 October 2018 / Published: 30 November 2018

\begin{abstract}
A thorough investigation of a polymer was performed for corrosion of mild steel in $1 \mathrm{M} \mathrm{HCl}$ solution using electrochemical and surface studies. Infra-red spectroscopy was completed in reflectance mode to detect the adsorption of the polymer on the metal surface. Scanning electrochemical microscopy (SECM) studies were made to detect the localized corrosion reaction at the working electrode. Electrochemical impedance spectroscopy revealed that the efficiency of corrosion inhibition was improved after the addition of polymer in the solution. Polarization studies suggested that the polymer belong to the mixed category mitigators. Scanning electrochemical microscopy (SECM) studies suggested that the surface was insulating in presence of polymer thereby protecting the surface. Scanning electron microscope (SEM) suggested that the surface was less corroded in presence of polymer.
\end{abstract}

Keywords: SECM, Polymer, SEM, FTIR, Mild steel, EIS

\section{$\underline{\text { FULL TEXT }}$}

(C) 2019 The Authors. Published by ESG (www.electrochemsci.org). This article is an open access article distributed under the terms and conditions of the Creative Commons Attribution license (http://creativecommons.org/licenses/by/4.0/). 